\title{
Analysis of L-dopa induced dyskinesias in 51 patients with Parkinsonism
}

\author{
R. J. MONES, T. S. ELIZAN, AND G. J. SIEGEL \\ From the Department of Neurology, Mount Sinai Medical School, New York, New York, U.S.A.
}

SUMMARY An analysis of 51 patients with Parkinsonism who have developed L-dopa induced $\mathbb{Q}$ dyskinesias is presented. The cause has not been proven, although various hypotheses are discussed One third of the total number of patients treated developed dyskinesia. These patients tend to re- 0 spond better to L-dopa than the other group. There is a tendency for the older patient or the patientwith long-standing disease to develop dyskinesias. There appears to be no way of predicting which $\vec{\omega}$ patients will develop dyskinesia by analysis of the symptoms or the aetiology of the Parkinsonisms syndrome. The unilateral characteristic of the dyskinesia in patients with hemi-Parkinsonism anco patients with unilateral thalamotomies suggests that structural abnormalities are critical in deter $\stackrel{\dot{\phi}}{\oplus}$ mining the presence and localization of dyskinesias. This is supported by non-occurrence of similarlyos treated patients without Parkinsonism.

L-dopa is now established as the treatment of choice for Parkinsonism. Many articles have appeared in the literature since the initial work of Cotzias, Van Woert, and Schiffer (1967), Cotzias, Papavasiliou, and Gellene (1969) concerning the use of chronic high dose oral treatment with L-dopa. Most authors have found the drug of great help in approximately $50 \%$ of patients (Duvoisin, Barrett, Schear, Hoehn, and Yahr, 1969; Yahr, Duvoisin, Schear, Barrett, and Hoehn, 1969; Mones and Elizan, 1969; Elizan and Siegel, 1970). These patients have a change in their life style and a definite improvement in their symptoms in the periods of at least one to three years of observation. It has not yet been established if the drug stops the progression of the disease on a long-term basis. One of the most important and fascinating complications of the drug is the induction of dyskinesias. This paper is an analysis of L-dopa induced dyskinesias seen in 51 patients with Parkinsonism treated at the Mount Sinai Medical Center.

\section{METHODS}

The patients in this series of 152 were treated at the Mount Sinai Medical Center, from 1 November 1968 to 31 October 1969. The initial 60 patients were all first treated in the hospital and then followed as outpatients on a monthly basis. Of the next 90 patients, 45 have had treatment started in the outpatient department and 45 started in the hospital. The protocol for the medical and neurological evaluation of these patients, the followup care, and the laboratory data are included in a pegevious paper (Mones, 1969). The dyskinesias were evaluated by clinical history, neurological examination and $\Phi y_{-}$ ciné films of selected patients. The dosage of L-dopaco was between 3 and $6 \mathrm{~g}$ per day and the longest treatment period in this series is 12 months.

\section{RESULTS}

Involuntary irregular movements have been observecต during L-dopa therapy in 51 patients. These are most commonly seen in the facial muscles, jaw, $\overrightarrow{0}$ tongue, and neck, and consist of irregular fast and $\beta$ slow movements which can be categorized as combination of choreiform movements, athetosis and dystonia. These dyskinesias are irregular, occurs at different times of the day, but most commonlyo are decreased or absent in the morning hours Other abnormalities have been noted, including dystonic movements of the limbs and involuntaryo flexion of the toes. Other more bizarre movements of the trunk, with irregular hip or shoulder move-? ments, have been seen. Less common are abnormal respirations such as panting or sighing respiration? and forced inspiratory spasms and dyspnoea Involuntary eye movements have not been seen. These patients are frequently not aware of early 0 minor facial dyskinesias, but later these movements ${ }_{\mathrm{W}}^{N}$ 
may become embarrassing and a severe disability. In 25 of the 51 cases, the dyskinesias limited the amount of L-dopa that could be given and decreased the efficacy of the drug.

A total of 152 patients were started on L-dopa at the Mount Sinai Medical Center up to 31 July 1969 (Table 1). These cases of Parkinson's disease have been evaluated for this study, as they had been on the drug for at least three months. By 31 October 1969, 51 cases had developed dyskinesias at some time during their L-dopa therapy. None of 12 patients with various diseases of the nervous system other than Parkinsonism who have been started on L-dopa developed induced dyskinesias.

The dosage of the drug at the time of the onset of dyskinesias is shown in Table 2. The month of L-dopa therapy in which the dyskinesias occurred

TABLE 1

PATIENTS WITH PARKINSONISM EVALUATED (152)

\begin{tabular}{lcc}
\hline A. Improved with L-dopa & & Induced dyskinesias \\
\hline Dramatic & 13 & 11 \\
Good & 63 & 28 \\
Mild & 37 & 11 \\
\hline B. No help & 22 & 1 \\
\hline C. Stopped L-dopa & & 0 \\
Died & 6 & 17 \\
Cardiac problems & 2 & \\
Psychiatric problems & 3 & \\
Rash & 1 & \\
Fever & 1 & \\
Other causes & 4 & \\
\hline
\end{tabular}

TABLE 2

DEVELOPMENT OF L-DOPA INDUCED DYSKINESIA RELATED TO MONTH AND DRUG AND DOSAGE LEVEL AT TIME OF ONSET OF DYSKINESIAS

\begin{tabular}{cccccccc}
\hline Months on L-dopa & \multicolumn{6}{c}{$L$-dopa dose (g/day) at onset of dyskinesias } \\
\cline { 2 - 7 } & $1-2$ & $2-3$ & $3-4$ & $4-5$ & $5-6$ & $6-7$ & Totals \\
\hline 1 & & & & & & & \\
2 & & 1 & 7 & 1 & 2 & & 11 \\
3 & & 7 & 1 & 3 & & 12 \\
4 & 1 & 4 & 4 & 4 & & 13 \\
5 & & & 2 & 1 & 3 & 1 & 7 \\
6 & & & 1 & & 2 & & 3 \\
7 & & & 1 & & & & 1 \\
8 & & & & & & & \\
9 & & & & & & & \\
10 & & & & & & \\
11 & 3 & 25 & 8 & 14 & 1 & \\
12 & & & & & & \\
\hline
\end{tabular}

is also indicated. The majority of patients developed their dyskinesias while on a dosage of 3 to $6 \mathrm{~g}$ daily. Most of the patients developed their dyskinesias by the fifth month of therapy.

Table 1 lists the relationship of the induction of dyskinesias to the improvement of the patient on L-dopa therapy. The criteria for improvement have been relatively simple. Patients are considered to have (1) no improvement, (2) mild improvement, (3) good improvement, implying a change in life style so that if the patient was unable to work he is now working, or if the patient was unable to care for himself, he is now able to care for himself, or (4) dramatic improvement. Of 152 cases, 13 patients had a dramatic improvement on the drug, and of these 13,11 had some type of dyskinesia (Table 1). Sixty-three cases had a good result with L-dopa therapy, and 28 of these had induced dyskinesias. Of 37 patients who had mild improvement on the drug, only 11 had induced dyskinesias. Of 22 patients who had no help from L-dopa, only one patient developed dyskinesias. It appears that patients who do well with L-dopa have a high percentage of induced dyskinesias. This may imply that the improvement of a patient on L-dopa therapy is related in some way to the induction of dyskinesias. It must be noted, however, that many patients with dramatic improvement or good improvement in their Parkinson's disease did not develop dyskinesias.

The cause of Parkinsonism was analysed in this series. Seven patients had post-encephalitic Parkinsonism and of these, five showed significant clinical improvement and two developed dyskinesias. Of the idiopathic type represented by 145 cases, 71 improved significantly and 49 developed dyskinesias. No conclusion can be drawn relating type of Parkinsonism to induction of dyskinesias.

Nine patients in this series had bilateral thalamotomies and only one patient developed dyskinesias, which is a figure much lower than the general overall percentage (Table 3 ). This patient developed bilateral facial grimacing and respiratory abnormalities. Thirteen patients had previous unilateral thalamotomies, and of these seven developed dyskinesias.

TABLE 3

EFFECT OF PREVIOUS THALAMOTOMY FOR PARKINSONISM

\begin{tabular}{|c|c|c|c|}
\hline & $\begin{array}{l}\text { Patients } \\
\text { (no.) }\end{array}$ & $\begin{array}{l}\text { Significant } \\
\text { clinical } \\
\text { improvement } \\
(\text { L-dopa })\end{array}$ & $\begin{array}{c}\text { L-dopa } \\
\text { induced } \\
\text { dyskinesia }\end{array}$ \\
\hline $\begin{array}{l}\text { Bilateral operation } \\
\text { Unilateral operation } \\
\text { Non-operated } \\
\text { patients }\end{array}$ & $\begin{array}{r}9 \\
13 \\
130\end{array}$ & $\begin{array}{l}6 \\
5\end{array}$ & $\begin{array}{l}1 \\
7\end{array}$ \\
\hline
\end{tabular}


There were no unilateral limb dyskinesias seen contralateral to the thalamotomy. Five patients who did have unilateral limb dyskinesias all had their movements ipsilateral to the thalamotomy.

Table 4 shows that there is no definite statistical correlation between dyskinesia and duration of Parkinson's disease before L-dopa. However, it appears that the longer the disease has been present, the greater the incidence of L-dopa induced dyskinesias.

The relationship of dyskinesias to severity of the Parkinson's disease was analysed (Table 5). Patients graded as having a mild disease have evidence of extrapyramidal syndrome but are not disabled and can do their normal work or housework; moderate Parkinsonism implies difficulty in working, but some ability to care for themselves in their everyday living activities; severe Parkinsonism implies inability to work or care for themselves with the need for nursing help. Again there is a tendency for the more severely disabled patients with the longer history of the disease to have a greater incidence of dyskinesias.

An analysis was made of the predominant symptoms of Parkinson's disease before treatment with L-dopa and before induction of dyskinesias (Table 6). No conclusion is possible concerning a relationsip between the predominant symptom of Parkinsonism and the induction of dyskinesias from L-dopa.

TABLE 4

YEARS WITH PARKINSON'S DISEASE BEFORE STARTING L-DOPA

\begin{tabular}{lccc}
\hline Years & Total patients & $\begin{array}{c}\text { L-dopa } \\
\text { significant } \\
\text { improvement }\end{array}$ & $\begin{array}{c}\text { Patients with } \\
\text { L-dopa induced } \\
\text { dyskinesias }\end{array}$ \\
\hline $0-2$ & 19 & 10 & 2 \\
$2-5$ & 46 & 26 & 15 \\
$5-10$ & 61 & 30 & 26 \\
Over 10 & 26 & 10 & 8 \\
\hline & 152 & 76 & 51 \\
\hline
\end{tabular}

TABLE 5

SEVERITY OF PARKINSONISM BEFORE TRIAL OF L-DOPA

\begin{tabular}{lccc}
\hline Severity & $\begin{array}{c}\text { Patients } \\
\text { (no.) }\end{array}$ & $\begin{array}{c}\text { Significant } \\
\text { clinical } \\
\text { improvement } \\
\text { L-dopa }\end{array}$ & $\begin{array}{c}\text { L-dopa induced } \\
\text { dyskinesias }\end{array}$ \\
\hline Mild & 34 & 18 & 10 \\
Moderate & 59 & 34 & 12 \\
Severe & 54 & 24 & 29 \\
Bed-ridden & 5 & 0 & 0 \\
\hline
\end{tabular}

TABLE 6

PREDOMINANT ABNORMALITIES IN THE PATIENTS WITHO PARKINSONISM WHO DEVELOPED L-DOPA INDUCED DYSKINESIAS

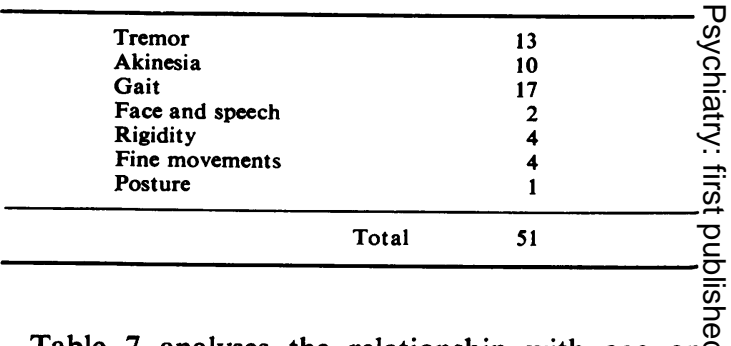

Table 7 analyses the relationship with age on $\stackrel{\mathbb{2}}{\circ}$ starting L-dopa therapy. No conclusion is possible, $\infty$ although it is noted that the percentage of dyskinesias $\vec{\circ}$ in the oldest age group is low. This may be due to thefact that this group tends to have greater difficultyc with L-dopa and a higher incidence of nausea, vomiting, and hypotension. The general inclination of the physician is not to increase the L-dopa to toxic levels in the older age group, in view of the $e_{\sigma}^{+}$ greater risk of hypotension and possible complica tions.

Twelve patients treated with L-dopa had diseaștso other than Parkinsonism (Table 8). The dosage

TABLE 7

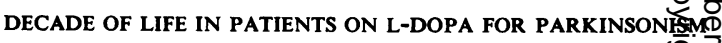

Age $\begin{gathered}\text { Total number } \\ \text { of patients }\end{gathered} \begin{gathered}\begin{array}{c}\text { Significant } \\ \text { clinical } \\ \text { improvement } \\ \text { L-dopa }\end{array} \\ \begin{array}{c}\text { L-dopa induesd } \\ \text { dyskesias }\end{array}\end{gathered}$

\begin{tabular}{rrrrr}
\hline $30-39$ & 1 & 0 & 0 \\
$40-49$ & 10 & 10 & 4 & 10 \\
$50-59$ & 34 & 19 & 30 \\
$60-69$ & 71 & 32 & 7 \\
$70-79$ & 36 & 15 & 51 \\
\hline & 152 & 76 & \\
\hline
\end{tabular}

TABLE 8

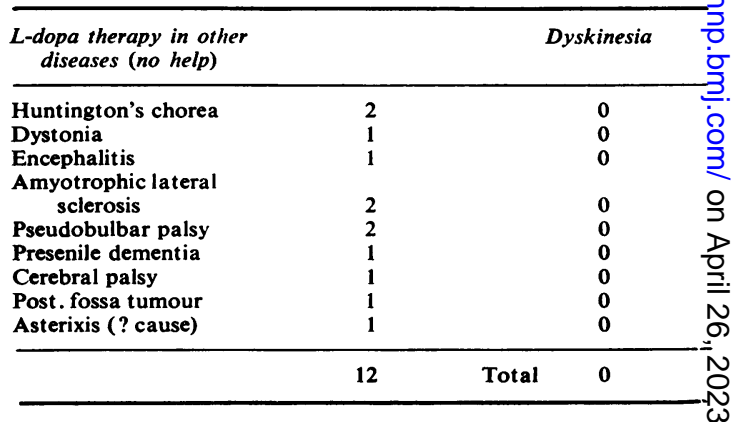


L-dopa in these patients was 4 to $7 \mathrm{~g}$ /day; however, no patient in this group was treated for more than four months. There was no improvement in the clinical condition of these patients, nor were any induced dyskinesias seen.

The area of induced dyskinesias in the patients with Parkinsonism was analysed, without considering the severity of the dyskinesia. Table 9 shows that in the unoperated patient group, there were 43 patients who developed dyskinesias while on L-dopa. No involuntary eye movements were noted. The Parkinsonism was asymmetrical in 18 patients. Dyskinesias occurred in the more involved side (arm or leg) in 14 of the 18 patients, whereas in only four cases were abnormal limb movements seen in the less severely involved limb. The one patient with bilateral thalamotomy developed breathing difficulties (sighing, panting respirations) and facial movements, but did not develop limb dyskinesias. The above data concerning the areas of induced dyskinesias in thalamotomy cases and unilateral cases of Parkinsonism are important and will be discussed further in this paper. It is apparent that anatomical abnormalities in the brain do have some effect on the types of dyskinesias seen when L-dopa is given.

\section{DISCUSSION}

Previous workers using prolonged oral L-dopa in the treatment of Parkinson's disease have described dyskinesias in approximately 30 to $50 \%$ of patients (Cotzias et al., 1967; Yahr et al., 1969). Duvoisin et al. (1969) noted, in 1968, that unilateral dyskinesias in the limbs appeared on the uninvolved side of patients with hemi-Parkinsonism.

TABLE 9

AREA OF INDUCED DYSKINESIAS

\begin{tabular}{lc}
\multicolumn{1}{c}{ Area } & No. \\
\hline Unoperated (43) & \\
Face-mouth-jaw & 33 \\
Asymmetrical Parkinsonism & 14 \\
More involved side & 14 \\
Less involved side & 4 \\
Trunk & 3 \\
Breathing apparatus & 3 \\
Bilateral limb & 6 \\
Unilateral limb in symmetrical Parkinsonism & 1 \\
Thalamotomy cases & \\
Unilateral (7) & \\
Ipsilateral movements & 5 \\
Contralateral movements & 0 \\
Face and jaw & 4 \\
Breathing apparatus & 1 \\
Face and jaw & 1 \\
\hline
\end{tabular}

The experimental induction of involuntary gnawing movements by the use of L-dopa in rats and rabbits after premedicating these animals with monoamine oxidase inhibitors was reported by Ernst (1965) and Ernst and Smelick (1966). The jaw, face, and mouth movements seen in humans taking L-dopa are strikingly similar to these gnawing movements. Apomorphine, which has a chemical structure similar to L-dopa (Figure), also causes similar gnawing movements in animals (Ernst, 1965). This suggests that these experimental dyskinesias are caused by stimulation of the dopamine receptors in the basal ganglia and may be analogous to L-dopa induced dyskinesias. Cotzias, Papavasiliou, Fehling, Kaufman, and Meng (1970) reported recently that the Parkinsonism syndrome is transiently improved with the use of apomorphine. This is additional evidence that apomorphine reacts with dopamine receptors and can simulate the action of L-dopa. Perhaps artificial compounds can be developed which will stimulate the dopaminergic receptors and improve Parkinsonism but will not cause complications such as nausea, vomiting, hypotension, or psychiatric difficulties or dyskinesias. It is not yet clear if the two actions of L-dopa and apomorphine-that is, improvement of the Parkinson's syndrome and the induction of dyskinesias - can be separated so that compounds can be developed that will help the Parkinson's syndrome but not induce the dyskinesias. The work of Ernst (1965) is of great interest, as an attempt has been made to control animal dyskinesia with various drugs. Some success has been reported with haloperidol, bulbocapnine, and drugs with a methoxy group in the para position (Figure).

Any conclusions as to the cause of dyskinesias during L-dopa therapy would have to explain the following clinical facts which we have observed: (1) Many patients have an excellent response to L-dopa on a stable dosage, without dyskinesias, only to develop this problem after three to four months of L-dopa therapy. The Parkinsonism syndrome may be improved during this period and there is no regression of the Parkinson's disease when the dyskinesias occur. (2) Patients may have excellent response to L-dopa and have no dyskinesias for a number of hours during the day. The occurrence of dyskinesias does not eliminate their previous improvement in the Parkinson's disease. Thus the response of the Parkinson's disease and the production of the dyskinesias are distinct phenomena which can be separated in time. (3) A reduction of L-dopa dosage to as little as $500 \mathrm{mg}$ a day may eliminate the induced dyskinesias within hours, or at least days. (4) The dyskinesias have not been observed in patients without Parkinsonism. This 


\section{ANTI-PARKINSONISM DRUGS DRUGS WHICH CAUSE A STATE RESEMBLING PARKINSONISM}

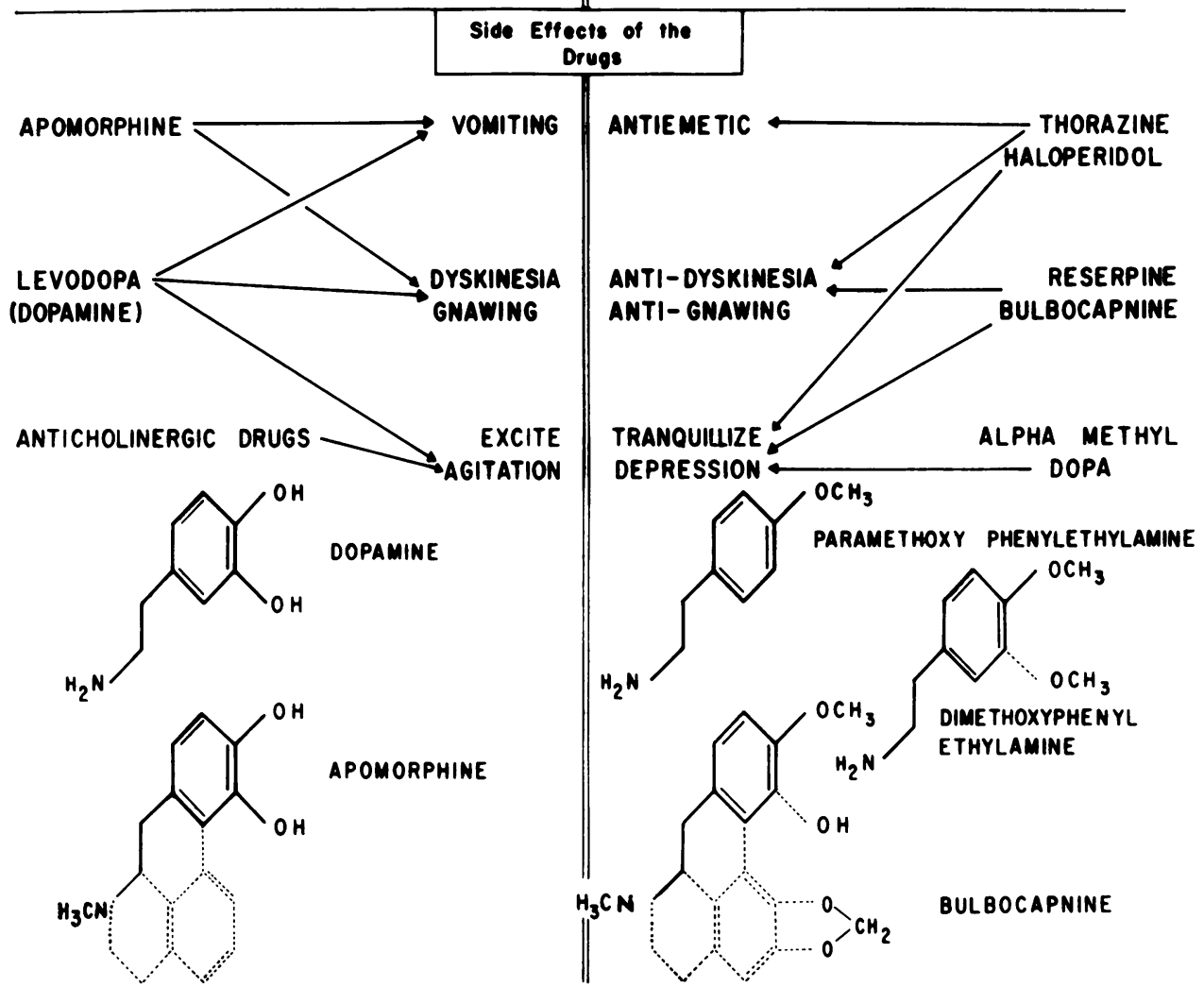

FIGURE This Figure attempts to show the similarities of diverse drugs that affect basal ganglia function. Note that dopa (dopamine) and apomorphine both relieve Parkinsonism and have side-effects: (1) vomiting and nausea, (2) dyskinesias, (3) excitement, which are opposite to the side-effects of other drugs such as haloperidol thorazine, and reserpine, which can cause a state resembling Parkinsonism: (1) antiemetic, (2) antidyskinesia, (3) depression. In animal work, Ernst $(1965 ; 1966)$ has noted that apomorphine causes gnawing movements in rats. The three drugs drawn on the bottom right side of the Figure protected these rats from the induced dyskinesias. Note the presence of a paramethoxy group in these compounds. Such drugs may have a practical application in the future to protect patients from $L$-dopa induced dyskinesias.

implies some abnormality in the Parkinson brain which is the cause of the induction of these dyskinesias. (5) An analysis of dyskinesias described in this paper has shown a unilateral character to their distribution when there is evidence of unilateral brain disease. The patients with unilateral thalamotomies have dyskinesias ipsilateral to the thalamotomy, implying that the unilateral thalamotomy protects the contralateral limbs from these induced dyskinesias. However, these patients do develop bilateral facial and jaw movements. The incidence of dyskinesias in patients with bilateral thala- motomies is lower than the incidence in the entire 3 . group, which implies some protective phenomenon. Patients with hemi-Parkinsonism had a predominance of unilateral dyskinesias in their involved 0 limbs. (6) The predominance of jaw, mouth, tongue, and neck dyskinesias is interesting and may be o related to the fact that similar dyskinesias are induced in animals. (7) There appears to be an $\sigma$ individual susceptibility to a particular type of $N$ dyskinesia, with anatomical localization peculiar ్ㅗ 
to each patient. Patients may have phenomena in one limb which disappear when the L-dopa is reduced, but on increasing the L-dopa to a similar level, exactly the same anatomical area of dyskinesia reoccurs. (8) Patients frequently report an absence of dyskinesias at 7 to 9 a.m. with the reappearance of the phenomena two or three hours after the morning dose of L-dopa.

Although not proven, it appears that patients without Parkinsonism do not develop L-dopa induced dyskinesias. In addition to the dopamine decrease, there is a $50 \%$ decrease in serotonin (5-HT) levels in the basal ganglia of the brain in Parkinsonism. This abnormality is apparently unique to patients with Parkinsonism and might explain the induced dyskinesias. It has been found by Bartholini, Prada, and Pletscher (1968) that massive doses of L-dopa will decrease the concentration of serotonin in the basal ganglia of animals. This phenomenon is presumably due to the inhibition of monoamine decarboxylase which is necessary for the formation of serotonin (5-HT) from 5-hydroxytryptophan (5 HTP). It is therefore reasonable to conclude that the concentration of serotonin in patients on long-term therapy with L-dopa is gradually being reduced by blockade of the reaction of L-5HTP to 5-HT. The dyskinesias might be related to the lack of serotonin in the basal ganglia or to a change in the ratio between dopamine and serotonin in these patients. Animal work by Sourkes and Poirier (1968), Poirier, Sourkes, Bouvier, Boucher, and Carabin (1966), and Poirier, Bedard, Boucher, Bouvier, Larochelle, Olivier, Parent, and Sungh (1969) has shown that the concentration of serotonin in the basal ganglia of animals has some relationship to the formation of tremor and choreiform movements. In animals with midbrain lesions and ingested harmaline, the induction of tremor and choreiform movements was correlated with low serotonin levels in the basal ganglia. It is not yet known if 5 HTP would increase the serotonin levels in these animals and perhaps protect them from these experimental dyskinesias. Other observers have noted that the concentration of serotonin in the basal ganglia or the ratio of dopamine to serotonin has some importance in the production of tremor and chorea (Hassler and Bak, 1969; Goldstein, Battista, Anagnoste, and Nakatari 1969).

\section{REFERENCES}

Bartholini, G., Prada, M. da, and Pletscher, A. (1968). Decrease of cerebral 5-hydroxytryptamine by 3,4dihydroxyphenylalanine after inhibition of extracerebral decarboxylase. Letter to editor. J. Pharm. Pharmacol., 20, 228-229.

Cotzias, G. C., Van Woert, M. H., and Schiffer, L. M. (1967). Aromatic amino acids and modification of Parkinsonism. New Engl. J. Med., 276, 374-379.

Cotzias, G., Papavasiliou, P. S., and Gellene, R. (1969). Modification of parkinsonism-chronic treatment with L-dopa. New Engl. J. Med., 280, 337-345.

Cotzias, G. C., Papavasiliou, P. S., Fehling, C., Kaufman, B., and Mena, I. (1970). Similarities between neurologic effects of L-dopa and of apomorphine. New Engl. J. Med., 282, 31-33.

Duvoisin, R., Barrett, R., Schear, M., Hoehn, M., and Yahr, M. (1969). The use of L-dopa in parkinsonism, p. 185-192. In Third Symposium on Parkinson's Disease. Livingstone: Edinburgh.

Ernst, A. M. (1965a). Relation between the structure of certain methoxyphenylethylamine derivatives and the occurrence of a hypokinetic rigid syndrome. Psychopharmacologia, 7, 383-390.

Ernst, A. M. (1965b). Relation between the action of dopamine and apomorphine and their O-methylated derivatives upon the CNS. Psychopharmacologia, 7, 391-399.

Ernst, A. M., and Smelik, P. G. (1966). Site of action of dopamine and apomorphine on compulsive gnawing behaviour in rats. Experientia (Basel), 22, 837-838.

Goldstein, M., Battista, A. F., Anagnoste, B., and Nakatani, S. (1969). Tremor production and striatal amines in monkeys, p. 37-40. Third Symposium on Parkinson's Disease. Livingstone: Edinburgh.

Hassler, R., and Bak, I. J. (1969). Unbalanced ratios of striatal dopamine and serotonin after experimental interruption of strionigral connections in rats. p. 29-37. Third Symposium on Parkinson's Disease. Livingstone: Edinburgh.

Mones, R. J., and Elizan, T. S. (1969). A short-term evaluation of L-dopa therapy in 34 patients with Parkinsonism. J. Mt Sinai Hosp., 36, 503-515.

Mones, R. J., Elizan, T. S., and Siegel, G. J. (1970). Evaluation of L-dopa therapy in Parkinson's disease. N.Y. St. J. Med., 70, 2309-2318.

Poirier, L. J., Sourkes, T. L., Bouvier, G., Boucher, R., and Carabin, S. (1966). Striatal amines, experimental tremor and the effect of harmaline in the monkey. Brain, 89, 37-52.

Poirier, L. J., Bedard, P., Boucher, R., Bouvier, G., Larochelle, L., Olivier, A., Parent, A., and Singh, P. (1969). The origin of different striato- and thalamopetal neurochemical pathways and their relationship to motor activity, pp. 60-66. Third Symposium on Parkinson's Disease. Livingstone: Edinburgh.

Sourkes, T. L., and Poirier, L. J. (1968). Serotonin and dopamine in the extrapyramidal system. Advances in Pharmacology, Part 6A, pp. 335-346.

Yahr, M. D., Duvoisin, R. C., Schear, M. J., Barrett, R. E., and Hoehn, M. M., (1969). Treatment of Parkinsonism with levodopa. Arch. Neurol. (Chic.), 21, 343-354. 